\title{
Van bedkant tot celwand en terug
}

Citation for published version (APA):

van der Linden, S. (1989). Van bedkant tot celwand en terug. Rijksuniversiteit Limburg. https://doi.org/10.26481/spe.19891201jl

Document status and date:

Published: 01/12/1989

DOI:

10.26481/spe.19891201jl

Document Version:

Publisher's PDF, also known as Version of record

\section{Please check the document version of this publication:}

- A submitted manuscript is the version of the article upon submission and before peer-review. There can be important differences between the submitted version and the official published version of record.

People interested in the research are advised to contact the author for the final version of the publication, or visit the DOI to the publisher's website.

- The final author version and the galley proof are versions of the publication after peer review.

- The final published version features the final layout of the paper including the volume, issue and page numbers.

Link to publication

\footnotetext{
General rights rights.

- You may freely distribute the URL identifying the publication in the public portal. please follow below link for the End User Agreement:

www.umlib.nl/taverne-license

Take down policy

If you believe that this document breaches copyright please contact us at:

repository@maastrichtuniversity.nl

providing details and we will investigate your claim.
}

Copyright and moral rights for the publications made accessible in the public portal are retained by the authors and/or other copyright owners and it is a condition of accessing publications that users recognise and abide by the legal requirements associated with these

- Users may download and print one copy of any publication from the public portal for the purpose of private study or research.

- You may not further distribute the material or use it for any profit-making activity or commercial gain

If the publication is distributed under the terms of Article $25 \mathrm{fa}$ of the Dutch Copyright Act, indicated by the "Taverne" license above, 
Van Bedkant tot Celwand en TERug

\section{REDE}

in verkorte vorm uitgesproken bij de aanvaarding van het ambt var bizonder hoogleraar in de Rheumatologie an de Rijksuniversiteit Limburg op vrijdag, 1 december 1989

door

Sjef M. van der Linden

De leerstoel werd ingesteld namens de Nederlandse Vereniging voor kheumabestrijding (NVRB) 


\section{Van Bedkant tot Celwand en TERvG}

Het houden van een openbare Les in de huidige vorm sta.t in zekere zin op gespannen voet met het Mastrichtse onolerwis Systeem. Inmers, $U$ heeft anders dan de orator geen actieve inbreng. Eigenlijk zouden we thans in onderwijsgroepjes wan ongeveer 10 personen en onder leiding van een niet inhoudelijk deskundige moeten discussieëren over het thema:

\section{"Van Bedkant tot Celwand en TERUG".}

0 dient daarbij dan minstens in te gaan op twee aspecten. Ten eerste ligt er een zeker accent op het TERUG naar het ziekbed van de patient. Ten tweede wist de titel op een niet eindigende cirkel beweging. De titel van deze woordracht suggereert derhalve een zekere dynamiek. Inderdaad is er bimmen de Rheumatologie, zoals trouwens ook in andere gebieden wan de geneeskunde, héel wat "IN BEWEGING"

\section{Rheumatolgaie in Beweqing: Keep Moving}

onlangs hield Cats zijn afscheidsrede als gewoon hoogleraar in de theumatologie. Ik wil thans niet ingaan op het feit, dat een gewone leerstoel in de rheumatologie meer en neer bizonder. wordt, nu bizondere leerstoelen gewoner geworden zijn. Dit latste is te danken aan de voortvarende en patient videndelijke visie van de Nederlandse Vereniging voor Rheuma Bestrijding (NVRB). Deze vereniging streeft er met kracht nat aan elke Nederlandse Medische Faculteit, war hierin nog niet voorzien ys, eer leerstoel in de rheumatologie in te stellen. Geen luxe. indien men de totale ziektelast (Burden of Illness) veroorzajit door theumatische andoeningen in ogenschouw neemt. It hoet hierbij slechts het epidemiologisch Prewertief Dnderzok zoetermeer (EPOz), dat onder leiding stond van Prof. Dr. B.A. Valkenburg, in herinnering te roepen. Dit onderzoek, dat belangrijke gegevens verschafte met betrekking tot het woorkomen van rugkiachten, arthrose, osteoporose, rheumatoide arthritis en spondylitis ankylopoetica, illustreert duidelijk de warde voor de rheumatologie van op de oper populatie gericht epidemiologisch onderzoek woor ethologische (oorzakelijke), diagnostische wn therapeutische vraagstelingen. 
Tabe 1. 1. Epidemiologidin Freventiet onderzoek zoetermear (EPoz)

(Prot. Dr. H.A. Valkenburg 1979)

Rheumatische killachen

wedische hulp via huisats

Di.agnose via rheumitoloog
3.000 .000 Nederlanders

450.000

265.000

Wel wil ik ingaar op de titel wan de afscheidsrede van Cats. Deze luidde: "WAT OWS BEWOG". Het $1 \mathrm{igt}$ bij een inaugurele rede van een dankbare discipel van cats meer voor de hand te spreken in de onwoltooid tegenwoordige tija en zonder de pluralis Majestatis vorm. Aldus had de titel van deze les ook kunnen zijn "WAT MIJ BEWEEGT", echter dit zou te zeer wotivatie centraal gesteld hebber. Nee, aan motivatie ontbreekt het de Rheumatologie allerminst, noch aan BEWEGING. Toch wordt de beweging binnen de rheunatologie soms wel eens ter discusisie gesteld. Bepaalde specialismen of disciplines kan men wellicht karakteriseren door een leesteken. De Epidemiologie komt dan zonder twijfel het VRAAGEKEN toe. "Epidemiology confused established issues and shaded Black-khite" aldus H.A. Valkenburg toen hem onlangs als tweede Nederlander in de geschiedenis de witzonderlijke eer te beurt viel in Londen de jaarlijkse "Heberden Oration" te houden. Dee titel van de rede Iuidde: "ARE WE STILL MOVING?".

(Het antwoond was bevestigend en sloeg niet op werhuizen).

\section{If you don't know where to go, you will end somewhere else}

Het is, ik citeer uit de rede van Cats,: "De steeds groter wordende kloof tussen het praktische op ervaring en kennis berustende werk van een arts, en het experimentele onderzoek in het laboratorium" "die mij vanmiddag (en daarna) bezighoudt. Met andere worden, ik vat de draad Cats op. "His Master's Voice (of McMaster's Voice?)": wat mag men méér verlangen van een "Meester - Leerling" verhouding? In onze tijd gaan ontwikkelingen snel. Ex Is voortdurend BEWEGIMG binnen de Rheumatologie en de geneegkunde. Juist darom is het wel eers goed stil te staan en te kijken warheen we onderweg zijn: quo VADIS? Vragen war we heengaan is echter ontoerejkend. Het gat inmers om de koers: "IF YOU DON'T KNOW WHERE TO GO, YOU WILL END SOHEWHERE ELSE!" ", Vandar nu deze opsoming van de 12 punten, die ik vanmiddag met $\mathrm{t}$ bespreken wil:

* ORET ORBT

* RHEURA RESEARCH

* REDUCTIE zIEKTELIAST

* GENEZEN RN ZORG

* EFTECT METTNG: DOTNG MORE GOOD THAN WARM

* PATIENT OUTCOME: MULTIDIMIENSIONEEL

* PRIORITEITEN EN WAARDEN VANUIT DE PATIENT 


\section{* RATIONEIE DIAGNOSTIER EN INTERVENTIE \\ * DE 2EVEN SPRONG \\ * RETATIE ONDERZOEK, ONOERWIJS, PATTENTENZORG \\ * MULTIDISCIPLINARITEIT ONDERZOER \\ * RHEUMARESEARCH: WIE eEPAalt dE ROERS?}

\section{Urbi et orbi}

Now you should know where we are going in Mastricht! Aan het einde van deze eeuw en an de vooravond van 1992 mag echter best wat grootschaliger gedacht worden. Niet alleen aan de stad Mastricht, maar aan "URBI ET OREI" of tewel an de stad en de wereld.

In dit verband dient opgemerkt te worden, dat we er krachtdadig naar streven de regionale, nationale en inter. nationale samenwerkingsverbanden verder te versterken en uit te bouwer. Heerlen en sittard, doch ook steden als Roermond, wijn zeer nabij. Reeds nu bestaat er een goede samenwerking, deels op basis van research projecten, met de collegae Goei Thé, Houben, van der Tempel en Jacobs, die ik daarvor zeer dank. Verdere uitbouw is gewenst. Darbij dient uiteraard stellig met verschillen in taakstelling en werkwijze rekening gehouden te worden.

Ook Aken, Luik en Lewven, Genk en Hasselt zijn nabij. Tenslotte, via Keulen en Parijs leidt de weg nar pISA, alwaar onlangs de European Spondylarthropathy study Group (ESSG) classificatie criteria opgesteid werden (Progress In Spondy Arthropathy). De rheumatologie wordt inderdad meer er meer internationaal.

\section{Rheuma Research}

Het doel van de rheumatologie is het tot stand brengen van een vermindering van de ziektelast, voorzover deze bepald wordt door rheumatische aandoeningen. Hiertoe staan ter beschikking onderzoek, Onderwijs en Patientenzorg. De succesparameter voor al deze aktiviteiten is dan ook de mate warin een reduktie van de ziektelast daadwerkelijk bereikt wordt. De rheumatologie heef tot taak de aan gezondheid gerelateerde Levenskwalitedt te verbeteren (voor zover beperkt door rheumatische ziekten). In dit concept is de terugkoppeling van wesearch-" onderwis"., en patientenzorg alkiviteiten nar de geformuleerde doelstelling (vermindering ziektelast) een essentietel element. Hierin onderscheidt zich de geneeskunde van andere vormen van wetenschap. Research aktiviteiten kunen zich bij de arwezigheid van een omschreven doelstelling schijnbaar wij en onbeperkt ontwikelen. De research kan dan een sterk werkennend en verklarend karakter hebben. Feinstein, onlangs weer op bezoek in Mastricht, onschrijft dit type onderzoek als exploratief: wat zijn de fenomenen en hoe kunnen zij werklabro en begrepen worden?

Moleculaire biologie, biochemie en biofysica zijn in de latste decennia tot geweldige bloei gekomem en verschatien irzichten in biologische fenomenen in een mate warin dat tot voor kort woor onmogeligk gehouden werd. Ik noem hier slechts de 
bijdrage var de immunogenetica an de ontrateling van HLA Human Leacocyte Antigeng moleculen. Dit voorbeld moge illustreren, dat eer wisselwerking tusser kiniek, laboratorium en epidenlologie belangrijke toegevoegde warde heeft. Van bedrand tot Celwand an TEUC, gebruk makend van zowel Microscoop als Macroscoop.

Immers, wen watheng gedaan aan het ziekbed leidde tot de kontlusie, dat een deel der bloedtransusiereaties in feite veroorather door antistof vorming tegen witte bloedcellen. Dit was de geboorte van de ontdekking van het hLA systeem, waraan de internist Jor van Rood en zijn medewerkers (Leiden) een 20 belangrijke bijdrage geleverd hebben. Al spoedig bleek er een dudelijke associatie te bestaan tussen HLA-antigenen en ziekten. Reeds in 1973 werd een zeer sterke associatie beschreven tussen HLA-B27 en spondylitis arikylopoëtica (Brewerton et al., alsmede Terasaki al.). Deze bevinding werd spoedig gevolgd door de beschrijuing van de associatie tussen HLA-DW en theumatoide arthritis (stasny et al. I. Door middel wan wacroscopie, in ait geval het Epidemiologisch Populatie onderzoek Zoetermeer (EFOZ), en microscopie (Bloedbank Leiden) kon door Cats, Valkenburg, de Jongh en mijzelf het risiko voor eerstegraads verwanten van spondylitis patienten en voor HLA-B27 positieve personen uit de bevolking vastgesteld worden. Inmiddels is bij verder analyse in het laboratorium van het HLA molecull gebleken, dat ex tenminste zes variantvormen var HLA-B27 bestaan. TERUG naar de (inmidalels extra-murale) patient bleek, dat geen van deze varianten in verhoogde frequentie bij spondylitis patienten voorkomt.

De structurur wan het HA-B27 molecuul is thans nauwheurig bekend, ook de tertiaire struktuur. Welk antigeen afkomstig van welk micro-organisme past er in dit HLA-927 molecul? spondylitis is een ziekte op zoek naar zijn ziekmakend micro-organisme. Een wisselwerking tussen kliniek en laboratorium biedt de beste kansen op een oplossing.

Thans wil itk verder ingaan op vormen van rheumaresearch, daarbij opzettelijk de terminologie "basale" of "fundamentele" research vermijdend. Deze terminologie is op zich weinig verhelderend. Bovendien claimen de meest uiteenlopende disciplines dergelijke termen voor hun research aktiviteiten, waronder de epideniologie: "Clinical Epideniology: A Basic Science for Clumical Medicine" (Sacket et al.). Ik hanteer de indeling van Feinstein:

1. Explortief onderzoek: Wat zijn de fenomenen en hoe kunnen zij verklaard en begrepen worden? Dit onderzoek is in het algemeen ethiologisch en pathogenetisch gericht.

2. Interventioneel onderzok: Hoe kunen zlekteverschijnselen voorkomen, danwel beinvloed worden? veel onderzoek, dat betrekking heeft op diagnostiek en therapie, walt hieronder.

Exploratief anderzoek kan via verdieping wan kennis en inzicht oplossungen suggereren voor die rheumatische aandoeningen, warwoor thans nog geen adequate remedie bestaat. Dit type van onderzoek zal dus uiteindelijk de nieuwe wegen voor 
preventie en interventie noeten leveren. De werkzamherd van (toekonstige) therapieen zal echter steeds met kinisch epidemilogisch onderzaek vastgesteld moeten worden. De vraagstelling daarbij is telkens weer, of de (nieuwe) interventie voldoet aan de doelstelling: "Doing More Good than Harm". viteindelijk is slechts via preventie of interwentise ex vermindering wan de ziektelast te bereiken.

\section{Reductie ziektelast}

De ziektelast (Burcien of Illness) betreft zowel mortaliteit als morbiditeit. Dit latste omvt enerzijas symptomen als pijn en stijfheid en anderzijds functioneie beperkingen, die zowel van fysieke, emotionele, als sociale aard kunnen zijn.

Alereerst dient de ziektelast vastgestela te worden. Indicatoren daarvoor zijn prevalentie, incidentie en ziektedutr. alsmede het beslag op de gezondhejdszorgwoorzieningen. Nagegaan dient te worden, wik gedeelte van de ziektelast vermijdbar of ophefbaar is en welk gedeelte niet.

De onophefbare ziektelast bestaat uit beperkingen, symptomen en mortaliteit, warvoor geen werkzame preventie of genezing bestaat. De coewijzing van onderzoeksmiddelen dient niet slechts op zorg voor de patienten te richten, doch juist ook op research naar ethiologie, preventie en genezing.

De ophefbare ziektelast bestat uit beperkingen, symptomen en mortaliteit waarvoor wei een effectieve therapie of preventie bestaat. Toewijzing van researchmiddelen zou zich moeten richten op health care research met name naar de effectiviteit en efficientie van de werkzame interventie in de gezondheidszorg. Ten aanzien van de rheumatologie zijn belangrijke aanknopingspunten voor reduceerbare ziektelast: pijn, functionele beperking (zowel in fysieke als in psychosociale zin), afhankelijkheid en de prioriteiten van de patient. Men kan dit samenvatien onder verbetering van de lewenskwaliteit uit het oogpunt van de patient. Dit belang werd nog eens onderstreept door de recente resultaten van de enquete naar aanleiding wan het 10 -jarige bestaan van de Nederlandse Bond van Verenigingen van Patienten met Rheumatische Aandoeningen.

\section{Genezing en zorg}

Eij de kevze hoe de beperkte financiale middelen in te zetten voor (rheuma) research, 1 igt er onmiskenbas een spanningsveld tussen de belangen van de patienten van vandaag (en die van morger en overmorgen en ... (wie weet hoe lang? I) enerzijds en toekonstige patienten anderzijds. Howeed van de beschikbare researchmidelen dient gespendeerd te worden abn de verbetering van de situatie van de hudige patient en hoeveel aan die van de toekomstige patient? Is het hemb van de hudige patient rader dan de rok van de toekomstige patient? 
Laten we rheumatoide arthritis als en voorbeeld nemen. Haneer zal het zover zijn, dat deze andoening geheel te voorkonen (preventie), ow in een heel vroeg stadium optinal te genezen (cure) is? De behandeling moet dan platsvinden, poordat ex sprake is van enige funktonele beperking. De bijwerkingem wan de intervente dogen daarbij hooguit minimal zijn.

Hoe mot thans de verdeling zifn van de beschikbare midcilen tussen de doelstelling: "verbetering van de situatie van de huidige patient" en "het voorkomen of vroegtijdig behandelen van de toenombtige patient"? Het is duidelijk, dat in de komende jarter de discussie tussen patienten, providers (de verstrekkers van hulp, en payers (de betalers voor die hulp) verder zal anwakkeren.

\section{Effect Meting: Doing more Good Than Harm}

Doordat van veel rheumatische aandoentngen de oorzaak en de ethitopathogenese niet of onvoldoende bekend $z i j n$, is in de meeste gevallen een primaire preventie vooralsnog onmogelijk. Er zal dan ook nog heel wat onderzoek vericht moeten worden om nieuwe vormen van preventie en interventie te kumen toetsen. De beschikbare middelen zijn inmiddels schaars geworden. Er zijn grenzen an de groei en grenzen aan de zorg bereikt. Door thans te onderzoeken welke van de nu beschikbare therapeutische middelen voor een bepadd type patient het meest geëigende middel is, kan (bij een goede compliance van patienten en providers) het huidige therapeutische arsenaal ongetwijfeld beter benut worden. De vraag of rheumatoide arthritis patienten in een eerder stadium dan tot nu toe het geval is met steroiden en langzaam werkende antirheumatica behandeld moeten worden, "Remodeling the Pyramide" heeft hierop betrekking. Alleen goed opgezet epidemiologisch onderzoek rekening houdend met het natuurlijke beloop zal klaarheid kunnen brengen.

Hiermee moge duidelijk $\mathrm{zijn}$, dat effekt meting geen doed op zich is. Het is een middel waarmee vastgesteld kan worden war werkelijke outcome verbeteringen optreden. Daarbij is niet primair de statistische significantie (de zogenamde $p$ warde) relevant, doch de klinische betekenis van effekten.

In de toekomst zal in toenemende mate onderzacht moeten worden, welke faktoren een woorspellende (prognostische) warde hebben voor een verbetering van het eindresultat (outcome). Dit type epidemiologisch onderzoek zal meer en meer in de rheumatologie (en in de geneeskunde) toegepast gaan worden.

Interventies gaan gepaard met kosten van verschillende aard (bijwerkingen, ongemak, financieel). Effekt onderzoek leidt niet tot besparingen, doch kan wel anleiding zijn tot reallokatie van middelen. Ineficiënte zorg kost geld, dat beter elders besteed had kunnen worden: in effektieve interventie of in research aktiviteiten. In dit verband is het jammer te moeten konstateren, dat de districtsverpleegkundige in de rheumazorg nagenoeg verdwenen is, nog voordat de bijdrage van dit type zorg aan outcome verbetering van de patient met rheumatische aandoeningen onderzocht kon worden, inclusief een kosten effektiviteitsanalyse (KEA). 
Verwacht mag worden, dat met betrekking tot rheumaresearch in toenemende mate ook nietwedicanenteuze themaphe, warondex Eysiotherapie, onderwerp van effect studies, inclusief kosten Effectiviteitsanalyse zal gaan worden. Evaluaties, watubijalleen op de effecten van applicaties gelet wordt, zijn niet erg realistisch, daar dan voorbijgegaan wordt an de effecten van de patient-therapeut interactie. Het criterium voor voortzetting van) een fysiotherapeutische behandeling dient te zijn, of het ldoorgans fysieke) functioneren van de patient nog steeds verbetert, danwel of de therapie de patient voor een duideligke terugval in zijn functioneren behoedt. Er zigh de latste jaren zeer goede, goedkope en makkelijk toepasbare wragerilisten ter beschikking gekomen, die het functioneren betrouwbaar meten. Dergelijke questionalies kunnen (1) niet ziektem specifiek zijn. brjwoorbeeld de SIP (Sickness Impact profile), (2) ziektespecifiek zijn, bijwoorbeeld de AIMS (Arthritis Impact Measurement Scale) of de $\mathrm{HAQ}$ (Stanford Health Assessment Questionaire), of (3) patient-specifief zijn, bijwoorbeeld de MACTAR (McMaster Toronto Patient Preference Disability Questionacie), alsmede de utiliteitsmetingen bij patienten.

Ten anzien van dergelijke instrumenten thebben wij, behalwe met Mckaster, een wruchtbare samenwerking opgebouwd thet het Instituut woor Revalidatie Vraagstukken te Hoensbroek. Ik noen hier met name Luc de witte en Johan WIayen.

Gevalideerde Nederlandse versies en anpassingen ajon irmidels ter beschikking gekonen: de DurCh Alks (Tal, Jacobs, Seydel, Wiegman, Rasker), en de IRGL - Invloed keura op Gezondheid en Leven (Huiskes, Kraamaat, Bijlsma). Dergelijke vragenlijsten zijn niet alleen bruikbat in clinical trials, ook woor de dagelijkse praktijk werd het nut aangetoond. Daar voorts functionele beperkingen aldus duidelijk naar voren komen, kan de therapie zich nadrukkelijk darop richten. Functionele capaciteitstesten zign bovendien in stat morbiditeit en mortaliteit te voorspellen.

\section{Patient outcome: Multidimensioneel}

Wat moet de matstaf zijn bij de vermindering van de ziektelast? Is dit levensverwachtirg? onderzoek heeft angetoon. dat de gemidelde levensverwachting bij diverse inflanmatore rheumatische aandoeningen verkort is. Verlenging van het weyen, zonder darin de konditie of de funktionele tostand var de patient te betrekken, kan lesden tot een toename van de ziektelast. Nu enerzijas vele infektieziekten als de grote killers in onze westerse wexeld bedwongen zijn en anderzijas duidelijk wordt. dat veroudering een biologisch proces is en nit het resultat van zidekte en det het proces van veroudering biologische grenzen stelt aan de levensverwachting, wint geleidelijk het inzicht terrein, dat behoud respectievelijk herstel van gezondheid en levenskwalitedt de primaire doelste lingen zijn, warop gezondheidsorg en gezondheidsonderzoek zach noeter richten. 
Hoe gtelt men verbetering in de kinische situatie van en patient betrowbar vat? laten warbij in gedachten uitgaan ran een petient me thematolde arthritis. Welke bijdrage levert het makn van een nieuwe roentgenfoco, of het bepalen van de bloedbezinking? Aldus ontstat hooguit een incompleet beeld wan de patient. De arts: "Uw bezinking is veel beter en de foentgenfoto is nawelijhs verslechterd". De patient: "Dat is fijn dokter Irheuma patienten zijn altija ardig voor de dokterl, matir ik vol me niet beter, heb nog veel pijn ondanks de nieuwe tabletten, ik sav slecht, zie de toekomst somber in en ik heb meer woelte wjulf an te kleden dan een jaar geleden". Kortom. ex is niet én uitkonst (outcome), maar een hele reeks. Men vat ze wel samen als de 5 D" $\mathrm{E}$ : "Death (wortaliteit), Disability (beperingen), Discomfort (pijn, stijfheid, moeheid, ongemak), Drugr: (bijwerkingen wan medicatie), en Dollar costs (kosten voor de patient en de matschappij tengevalge van de ziekte. Daarander vallen ondermeer de kosten van arbeidsongeschiktheid en inkomsten del iving).

Meer en meer zullen research aktiviteiten zich gaan bezighouden met outcome management. Dit betekent het opzetten en instandhouden van data bases warin opgenomen worden de invioed wan interventies op de gezondheidstoestand en levenskwaliteit. Dit stelt patienten, payers en providers in stat gefundeerde keuzen te maken. Bovendien stelt outcome management dokters in staat (nog) betere providers te worden. De doelstellingen van dergelijke data bases dienen echter tevoren gedefinieerd te worden en zich noch tot de eerstem, noch tot de tweedelijn te beperken. Het verbast niet, dat population based registries vanut epidemiologische centra opgezet en onderhouden worden.

\section{Prioriteiten en Marden vanuit het gezichtspunt van de patient}

Dezelfde uitkomst van een ziekte bijvoorbeela een bepalde fysieke handicap) kan voor verschillende patienten een totaal andere betekenis hebben. In samenwerking met McMaster university schenken we (vooralsnog vooral in het kader wan research) ruime aandacht aan de prioriteiten, zoals een patient die zelf aangeeft en aan de wamden, die patienten zelf aan uitkomsten toekennen.

Is het netto-resultat van de diverse uitkomsten voor de patient met een chronische andoening toereikend? Is er sprake wan "Doing More Good Than Harm"? Is de gezondheidstoestand uit het perspektief van de patient verbeterd? Wat is het nut (de "utiliteit") voor de patient?

Van interventies zou dus niet alleen de effektgrootte, maar ook de warde van het effekt woor de patient voor zijn getondheidstoestand bekend moeten zijn.

\section{Rationel Diagmostiek en Interventie}

vit bewkingsonderzoek leerde de Nederlandse rheumatoloog, dat rheumaktaren vaker voorkomen bij grezonde personen, die geen rheumatoide arthritis hebben dan bij patienten met deze

aandosning. Derhalve zal de Nederlandse rheumatoloog bij een lage pretest (a priori) warschijnlijkheid, zoals bij gewrichts- 
steeds klein. Het feit dat de performance in de zin van ajagnostisch gedragl buiten de rheunatologische wereld in dit opzicht nog wel eens anders is, onderstreept eens te meer, dat kennis var epideniologische principes bij kan dragen tot Rationele Diagnostiek en Therapie en aldus kostenbeperkend kan werken. Intensivering van onderwijs in epidemiologie zou mog wel eens een zeer gunstige kosten/baten-verhouding kunnen opleweren!

De anamese kan een zeer krachtig, niet belastend, ongevar lijk en goedkoop diagrostisch instrument zijn. Twee simpele vragen hebben een sterk onderscheidend (discriminerendy vermogen tussen rugkiachter ten gevolge wan spordylitis ankylopoetica er non-spondylitis. Deze twee vragen luvaer:

(1) "Komt spondylitis ankylopoetica bij Uw (eerstegraadsil verwanten voor?",

(2) "heeft de rugpijn een inflammatoir karakter?" (Tabel z)

Tabei 2. Tntamatoire rugklachten

- Eegin var de kiachten voor het 40-ste jaar

- Tenminste 3 maanden (nagenoeg! constant aanwezig

- Geleidelijk begin

- Ochtendstijfheid langer dan 15 minuten

- Verbetering bij beweging

Inflamatoire rugklachten: bij 4 of meer "Ja" antwoorcen

Indien het antwoord op beide vragen ontkennend is, daalt de kans op spondylitis onder $0.1 \%$. Echter een persoon biy wie het antwoord op beide vragen bevestigend luidt, heeft $50 \%$ kams spondylitis te hebben (Figuur 1). Door gerichte verdere vragen en eenvoudig lichamelijk onderzoek kan de warschijnlijkheid nog hoger worden. Bloed-en roentgenonderzoek kan aldus zeer selectief en efficient aangewragd worden.

Ik schuw in dit verband ook het woord "Kosten-Effektivitejt" niet. Te wak wordt bij kosten effektiviteit direkt a an bezuiniging binnen de gezondheidszorg gedacht. Wen meer positieve benadering van kosten-effektivitext onderzoek ys het feit, dat aldus effecten onder éen noener gebracht kunnen worden. Kosteneffektiviteitsonderzok is miet alleen nutig voor de betalers (payers) van gezondheidszorguoorzieningen, doch ook voor de verschaffers ervar (providerg). Het biedt de mogelijkheid binnen eer vakgebued na te gaan war maximale effekten bereikt kumen worden. Immers, het inzetten van middelen op plats A betekent. dat dezelfde middelen niet meer op eer andere plats ingezet 


\section{NOMOGRAM}

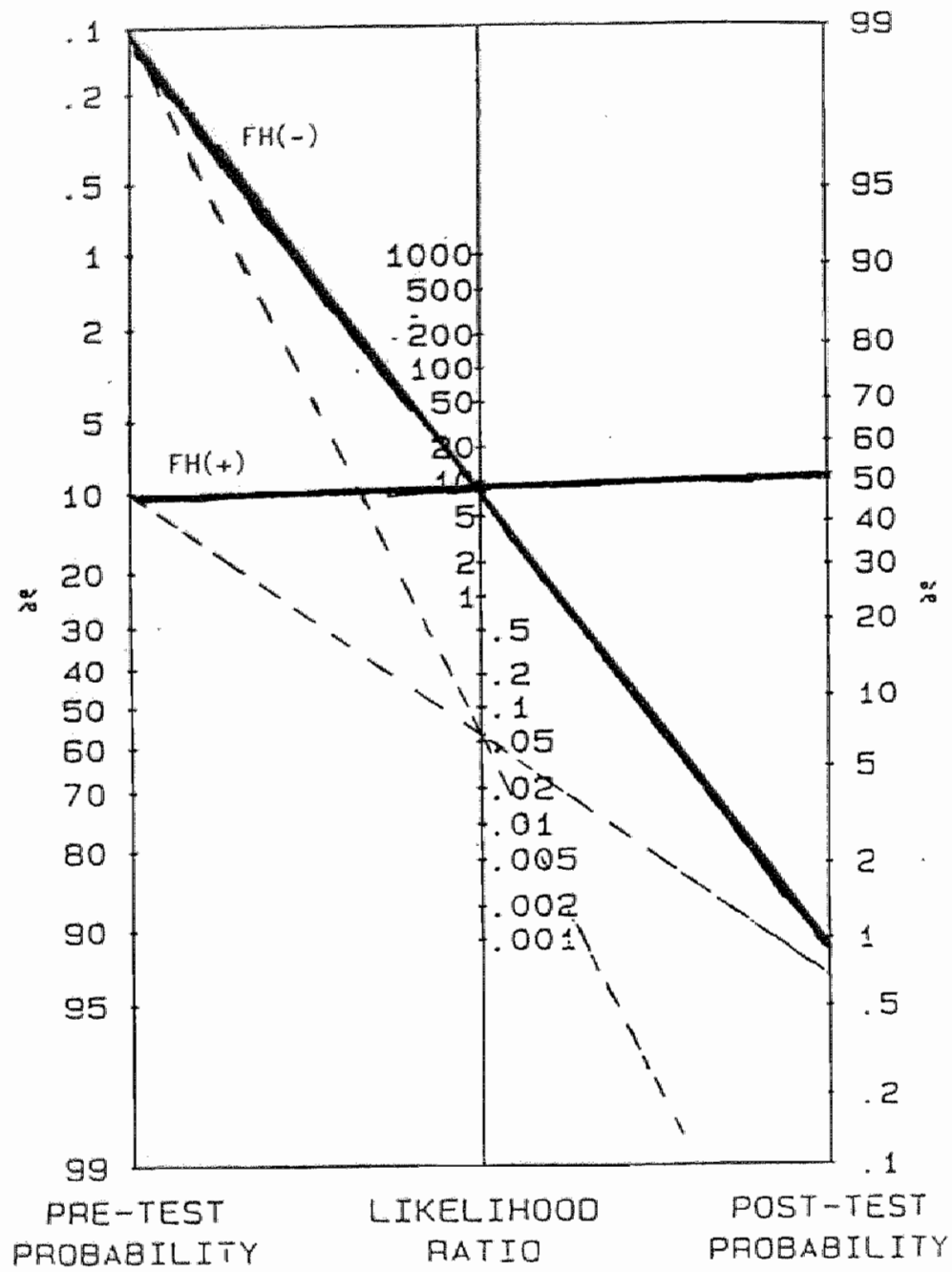


Figuur 1. De familie anamese en de armezigheid van inflamatoire rugklachten be hruloeden de warschijnlijkhald te lijden an spondylitis ankylopoetica (SA).

Pretest probability. Ongeveer 10 wan eerstegraadsverwanten van SA patienten heeft ook zelf deze aandoening. De prevalentie van de ziekte in de Nederdandse populatie bedraagt 0,13111 .

Likelihood Ratio. Ongeveer 95\% van SA patienten heeft inflammatoire rugklachten (sensitiviteit), terwijl zulke klachten evenems bij 10 : van controles zonder $S A$ anwexig zijn (fout positief) $(2-3)$. Hierult volgt een likel ihood ratio van ongeveer $95: 10$ ofwel 9,5 in de aanwezigheid van inflammatoire rugklachten en een likelihood ratio van $(100-95):(100-10)=5: 90$ of wel 0,055 in de afwezigheid ervan.

post test probability. Een verwant met (inflammatoire) rugklachten heeft volgens het nomogram ongeveer $50 \%$ kans SA te hebben. De kans daalt tot minder dan 1 , indien zulke klachten afwezig zijn. De post test warschijnlijkheid geldt reeds voordat de beweeglijkheid van de rug onderzocht is en voordat radiologisch onderzoek van de sacroiliacale gewrichten verricht is.

Woor een persoon met inflammatoire rugklachten, doch met een negatieve familie anamnese stijgt de test hans gering van slechts 0,4 naar $1,0 \%$. In de afwezigheid van zulke klachten daalt de kans tot minder dan $0,1 \%$.

$\mathrm{FH}(+)=$ Familie anamese positief woor $S A ; F H(-)=$ Familie anamese negatief voor $S A$.

Doorlopende lijn: inflamatoire rugkiachten aanwezig; onderbroken lijn: geen inflamatoire rugklachten.

1. Van der Linden SM, Valkenburg HA, de Jomgh BM, Cats $\mathbf{A}$ : The risk of developing ankylosing spondylitis in HL-B27 positive individuals: a comparison of relatives of spondylitis patients with the general population. Arthritis Rhew 1984;27:241-249

2. Calin $A$, Porta $J$, Fries JF, Schurman DJ: Clinical history as a screening test for ankylosing spondylitis. JAMA $1977 ; 237: 2613-2614$

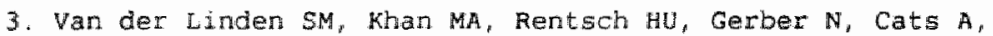
Valkenburg 4A, Tugwell PX: Chest pain without iadiogtaphic sacroilitis in relatives of patients with ankylosing spondylitis. I Rheumatol 1988;15:836-839 
Kunrers horden. Resultaten van kosteri-efektiviteitsonderzoek kunher helpen bij het meer rationeel waken wan beslissingen, welke ok zonder zulk onderzoek genomen zouden worden.

\section{De zever Sprong}

ven cixked, die in feite uit 7 stappen bestat ("De zeven sprong" , stelt ons in staat de beschikbare kennis te ordenen, leemtes vast te stellen en prioriteiten aan te geven. Voorts kan darme de bujdrage van verschillende disciplines aan het gezondheideprobleem in kaart gebracht worden. Deze 7 stappen worden in onderstaande tabel weergegeven (Tabel 3 ).

\section{Tabe 1 3. DE ZEWEN SPRONG in de GEZONDHEIDSZORG}

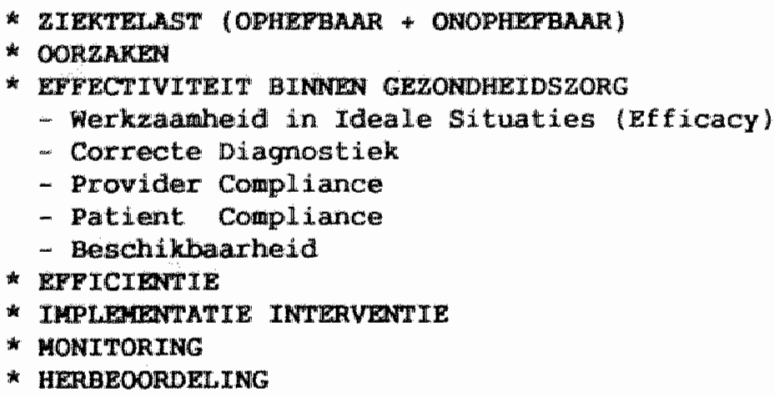

De eerste stap stelt vast, welk gedeelte van de ziektelast ophefbar is en welk gedeelte niet. Daarna wordt nagegaan, welke de oorzaken voor deze ziektelast zijn eri welke therapeutische matregelen hieruit voortvloeien.

In de derde stap wordt bekeken, welke interventies effectief zijn, niet alleen onder de ideale omstandigheden wan een ciunical trial, mat ook ondex de minder ideale onstandigheden var alle dag. Van belang voor daadwerkelijke reductie wan de ziektelast is, dat bij alle darwoor in aanmerking komende patienten tijdig de juste diagnose gesteld wordt. (Hieruit blijkt dus de warde van voldoende onderwijs en kennis en vaardigheden bij artsen, die door patienten met rheumatische andoeningen geconsulteerd worden. )

Na het stelien van de diagnose dient de juiste therapie ingesteld te worden. Tevens is van belang, dat de patient ach datian dan ook houdt. Goede motivatie en voorlichting over de ziekte en de therapie zijn derhalve wan groot belang. Daamaast dienen hulpverleners als rheumatolagen of orthopaedisch chirurgen binnen redelijke afstand bereikbaar te $z i j n$.

In de volgende stappen wordt nagegaan, hoe de efecten zich 
verhouden tot de kosten. Op grond van deze 4 stappen kunnen dan anbevelingen gedaan worcen om te komen tot een verdere vermindering van de ziektelast. De werking van een dergelijk programa dient dan nawkeurig nagegaan te worden. Uiteindelijk behoort een afname van de ziektelast vastgesteld te worden.

\section{Relatie onderzoek onderwis patientenzorg}

De beschrijuing van "De Zeven Sprong" makt reeds duidelijk dat - indien de werkathheid wan een interventie vaststat voor een daadwerkelijk succeswolle reductie van de ziektelast integratie van onderzoeksresultaten in onderwijs an patientenzorg noodzakeligk is. De mate warin deze beinvioeding plaatsvindt, dient op zich onderwerp van studie te zijn.

Gegeven een effektieve interventie, is de eerste stap in de vermindering van de ziektelast de detectie (diagnostiek) en vervolgens de therapie van die patienten, die voor de betreffende interventie in anmerking komen. Dit veronderstelt adequate kennis en vaardigheden, zowel in de eerste- als in de tweedelijns gezondheidszorg, van de betreffende theumatische aandoening. Hiertoe is onderwijs nodig, dat effektief kennis en viardigheden overdraagt. Een eerste vereiste is dan ook, dat zulk onderwijs an alde universiteiten met een medische faculteit in woldoende mate beschikbaar is. De Nota 2000 geet aan, dat meer din tot nu toe aandacht voor chronische ziekten en chronisch zieken nodig is. Onbeantwoord blijft vooralsnog hoe een en ander in concreet beleid vertald gat worden. Noblesse oblige.

Beslissend uit het oogpunt van vermindering van de ziektelast is het feit, of kennis en vardigheden in de prakijk in voldoencle mate en op het juiste moment het praktisch handelen beinvloeden (performance). Bijvoorbeeld, warden bij patienten met rheumatische andoeningen corrigeerbare of reversibele functionele beperkingen tijaig vastgestela? Hoeveel beter doen rheumatologen het in dit opzicht in vergelijking met niet Iheumatologen? Hoe snel worden de gewenste ampassingen gerealiseerd? Kan dit proces verbeterd worden? Leidt proces verbetering tot betere uitkomsten en tot besparingen? Dergelijke aspekten zijn binnen de rheumatologie nog weinig onderzocht.

Het is onvoldoende studenten te leren hoe gewrichten te onderzoeken, wat jicht is en hoe deze aandoeming behandeld moet worden. Darnast dient onclerzocht te worden, wat de daad werkelijke performance in de praktijk is en met name welke fatoren hierop eventueel een negatieve invlaed hebben. Jicht diagnostiek is namelijk eenvoudig en goedkoop. Tevens is de medicamenteuze behandeling tegenwoordig uiterst effectief. Chronisch destructive jicht kan net adequate behandeling (warronder begrepen goede patient en provider compliance) voorkomen worden. De therapie is goed te standariseren. In welke mate voldoet de jicht behandeling thars an het criterium: "Doing More Good Than Harri"? Hierbij moet aok gedacht worden aan de risico's en kosten wan lover behandeling van asyptomatische urinezur verhoging. Met andere woorden meer onderzoek zal erop gericht moeten zijn na te gaan, of datgene wat met de huidige kemnis en de beschikbare middelen reeds bereikt kan worden ook 
dadwextiy gehala word.

In het hulige gezondheldszorgsysteer wordt veel aandacht berwed ah exploretief orderzok en in zekere zin ook aan onderobk gerickt op het vaststelien van werkzaaneid. Echter de mate warin kennis en kunde omgezet worden in praktisch handelen, onderwndt doorgans weing andacht. Wellicht speelt hierbis eer rol, dat onderzoek, onderwijs en patientenzorg teveel als aronderlijke aktiviteiten gezien worden. Ik roep in dit verband in hertnnering, dat ook op macro niveau gezondheidszorg, onderwije en onderzoek niet duidelifk als samenhangend gezien worden. Immers, gezondheidszorg aam de ene kant en onderwijs en onderzoek aan de andere kant zijn over de ministeries van wW en onderwis wetenschappen verdeeld.

\section{Muld Hociplinais onderzoek}

Het onderzoek HIA-B27 en spondylitis ankylopoetica 11.lustreerde, hoe zinvol een programatische koppeling van ethiologisch gericht onderzok met diagnostisch (of therapeutisch) onderzoek zijn kan en ook duidelijk voorwaarden schept voor de kinische cellantie darvan. Van Bedkant naar Celwand en TERUG.

Dezelfide formule passen wij toe bij het Lyme Borreliosis onderzoek. Welke Borreliz antigenen hebben pathogene betekenis voor de Lyme arthritis en hoe kan aldus de serologische diagnostiek van deze aandoening werbeterd worden? Dit onderzoek wordt uitgevoerd tesamen met de afdeling Microbiologie

(A. Blaauw, L. Nohlmans, T. wan de Boogaard, C. van Bovenl.

ook in het fibromyalgie onderzoek trachten wj ethiologische vragen te combineren met therapeutische problemen. In dit verband werd gekozen voor een multidisciplinaire benadering warbij betrokken zijn psychologen, sociaal psychologen, voorlichtingsdeskundigen, bewegings-wetenschappers, epidemiologen, statistici, economen en rheumatologen. De (incomplete) lijst van medewerkers bevat de volgende namen:

N. Groenman, J. Vlaeyen, L. de Witte, F. van der Horst,

J. Kleynen, A. Visser, P. Leffers, H. Schouten, E. van Doorslaer,

F. Verstappen, H. Janssen, C. Bakker, P. Bolwijn, H. Bouben,

H. Goei Thé, en als "First Lady" M. van Santen-Hoeuftet.

Multidisciplinair pragrammatisch onderzoek is verrijkend

voor 1 le participanten, biedt allerhande aanknopingspunten woor een bredere blik op de geneeskunde (in casu de rheumatologie), is mede bepalend voor de kwaliteit van onderzoek en vak beslissend voor de klinische relevantie ervan. In vele gevallem is het gewenst, dat de rheumatoloog als dirigent fungeert.

Epidemiologische scholing en training is daarbij een groot voordeel. In dit verband dank ik zowel Arnold Cats als tans Valkemburg voor het feit, dat $2 i j$ mij met SGO ondersteuning nar Mcwister dirigeerden en daatbij eigen belangen geheel opzi schover, 
Rheunaresearch: Whe bepaalt de koers?

De gereeskunde kont meer en meer in een financiele krisis terecht. Dit zal ongetwifeld invloed hebben op de rheumatologie. In zekere in lijdt de geneeskunde schipbreuk an het succes. Elk jaar kunnen we meer doen voor meer andoeningen waraan vroeger niets of veel minder gredaan kon worater. In vele grevallen is nog anvoldoende uitgezocht of meer doen ook daadwerkelijk leidt tot betere levenskwaliteit. Cebieden, war thans duidelijk meer gedaan kan worden, betreffen onder andere gelejdingsstoornissen wan het hart, ischemische hartziekten, niervergiftiging, maligniteiter of funktieverlies van gewrichten. Er ontstonden technologieen als pacemaker implantatie, transplantatie, dialyse, bestraling met hoge energie, nieuwe cytostatica en chemotherapeutische regimes, alsmede gewrichtsprothesen. Er ijin grenzen bereikt aan wat het publiek en de overheid bereid is te betalen. Weer doen op een bepaald gebied betekent straks undea kunnen doen elders. Hoe moet de verdeling zijn tussen acute en chronische ziekten, tussen ziekten met hoge en lage mortaliteit, tussen ziekten met hoge en lage morbiditeit? zeer moeilijke vragen. Laten we ons even beperken tot de rheumatologie. Moet er een Strategisch Beleidsplan Rheuma Research konen? Discussies zijn gaande.

wie bepalt de koers ten aanzien van de rheumaresearch? Vaart de kapitein-onderzoeker op eigen initiatief of meer men in opdracht van een rederi.j? Onderzoeksvragen en de resultaten van onderzoek trekken in toenemende mate de aandacht van policy makers. Dit geldt ook voor fondser. Het preventiefonds subsidieert alleen werkelijk preventief onderzoek en de ontwikkelingsgeneeskunde zicht zich sterk op technolagy assessment (TA). De onderzoeker van de 90 -er jaren wardt minder en minder een ontdekkingsreiziger. zijn koers wordt meer en meer op macro-niveau bepaald. Wie stelt de prioriteit? Ex is in toenemende mate sprake van overleg tussen de drie partners: patients payers en providers.

Bij dit alles ontstat het gevaar dat onderzoeker $(\mathrm{m} / \mathrm{w})$ verwordt tot aandrager van gegevens, tot een uitwoerder van opdrachten van anderen. Het risico bestaat, dat de gerichtheid op de patient en op het werminderen wan diens ziektelast in de knel komt. Hier zijn onderzokers met eer klinische betrokkenheid binnen een rheuna centrum in het voordeel. Dit onderstreept andermal de gewenste hechte relatie tusen onderzoek, ondewijs en patientenzorg.

Faculteit en Academisch ziekenhuis vergenakkelijken de tak van de onderzoeker niet direkt. Hij/zij komt terecht in een wereld van regels en richtijnen, van facultaire whematiek en zwartepunten met $z, S$ of stip. Motiveringen van het warrom $z$ ijn vaak moeilijk te achterhalen. Doel en middel lijken nogal eens gestrengeld. Het hoe en warom van gewenste afsteming van Eacultair en academisch onderzoek zijn tamelijk onduidelijk. Er zifn in dit opzicht TOPmDow en BOTrOM-UP benaderingen.

Hierarchieèn mogen het doel echter niet werhullen. Wat zijn de concepten en wat zijn de consequenties op korte en langere termign? Hoe evenwichtig dienen zwartepunten te zijn? 
Wat betekent een tweedeling warbis acultair onderzoek geidentificeerd wordt met "furdamented onderzok" en ziek whuisonderzow zich beperkt tot "patientgebonden onderzoek"? Ik hoop li initadels dudelijk gemakt tebben, dat een dergelijke irdeling weing verhelderend is. Ethioldgisch-en pathogenetisch onderzoek zifn ook patient gericht. Een indeling in exploratief lethialogisch / pathogenetischi en interventioneel (diagnostisch / therapeutisch) is, althans in aijn ogen, duidelijker. Ik wees ex reeds op, dat een programmatische koppeling van beide typen van onderzoek in een klinische setting vaak succesvol is. Derhalve zou een scherpe scheiding tussen tacultair onderzoek en acadenisch ziekenhuis onderzoek beslist een ongewente ontwikliling $z j \mathrm{jn}$. De aanwezigheid van zowel een Faculteit var de Geneeskunde als een Faculteit dex Gezondheidswetenschappen maakt het er sowieso niet gemakkelijker op, en omvattend beeld van de geneeskunde voor ogen te houden.

Wat zouden de uiteindelijke consequenties van zwartiepunt yorming binnen het onderzoek wan een Academisch ziekenhuis kunnen zijn? Zouden sommige kinische groepen direct wit de boot vallen? Dat is voorstuands niet zo waarschijnijjk. Mijn vertrouwen in de vindingrijkheid van onderzoekersgroepen is daarvoor te groot. zo zou men kunnen beargumenteren, dat veroudering van kraakbeen al op jeugdige leeftijd begint, indien men femuro-patellaire knie arthrose bij adolescenten onder het thema verovdering zow willen laten vallen. Blijft echter de vraag, of zulk "inpersen" en relewantie van onderzoek elkaar steeds goed verdragen. Een gewengte homogeniteit leidt dan al snel tot een sterke mate van heterageniteit.

Indier de vindingrijkheid of de relevantie te kort schieten, zou de consequentie kunnen zijn, dat vakgroepen nawhelijks meer enige onderzoeksprestatie kunnen leveren. Onderzoek, onderwijs en patientenzorg worden dan formeel ontkoppeld binnen een academisch ziekerihuis, hetgeen de inledaing tot werdwjnen van de betreffende discipline uit de instelling kan vormen. Ongetwijfeld kunner aldus "geamputeerde" academische ziekenhuizen overleven. Echter, hoe goed is de overlevingskwaliteit na amputatie? Er is gevaar voor verschraling bij gebrek aan multidisciplinariteit. Academische geneeskunde moet een zekere content validiteit hebben.

Een altarnatief is de verwerving wan onderzoksmiddelen op basis van de kwalitedt van de onderzaekswoorstellen, waaronder begrepen de sterkte van het design, gegeven de vraagsteling. Dit zou brede aandacht voor methodologie kwaliteitsbevordering met zich brengen. Inderdaad geen ongunstig neveneffect.

Het is fantastisch dat door middel van fondsen als het National. Rheumafonds en door verenigingen als de Nederlandse Veremiging Voor Rheumabestrijding leerstoelen ingesteld warden. zoals ik exder al opmerkte, vormt dit een duidelijk signaal varuit de verantwoordelijkheid woor mijjoenen patienten. Bij niew in te stellen leerstoelen zou met de betreffende universiteit echter ook over de continuiceit van onderzoek gesproken moeten worden. Nederlandse Vereniging Voor Rheunabestrijding "Let op Uw Saeck". 
Kort na mign entree in Mastricht verdween het facultaide thema "Het Bewegingsapparat". Dat ik toch mijn weg alhier gevonden heb, heeft veel te maken met mijn wooropleiding en met de steun en openheid van de Vakgroep Epideniologie. Voor latsto geroemde aspecten gat myn dank uit naar pietex Leffers, pau Knipschild, en Ferd Sturmans.

Voor de vaststelling van de lange termijn effecten van interventies bij chronische aandoeningen als rheumatoide arthritus zijn langdurige fall lown studies noodzakelijk. Howeel. onderzoekers zijn nog in stat middelen te verwerven voor echt langdurig followup onderzok (10 jaar of langer)? snelle pulticaties zijn uiteraard bij dit type onderzoek niet te verwachten. Bij een wersterking wan de trend warbij meer en meex onderzoek uit de derde in plats van uit de eerste geldstroom gefinancierd wordt, wordt het opzetten en onderhouden van langdurig followup onderzok steeds moeilijker. Dergelijk onderzoek is alleen mogelijk bij adequate structurele ondersteuning en verminderde afhankelijkheid van kortlopende subsidies. Dit laat onverlet, dat langdurig followup onderzoek goed geconcipieerd moet zijn en dat toetsing van dergeijjke voorstelien in dit kader van primait belang is. Naast kwantiteit van publicaties is het ook var belang andacht te schenken ar de moeilijkheidsgraad van implementatie en de kwaliteit wan het onderzoek. Followup onderzoek bij veel voorkomende aandoeningen heeft ook dan belangrijke conseguenties voor de gezondheidszorg indien de gezondheidseffecten $k i$ inisch relevant, doch relatief bescheiden zijn.

Tenslotte, gegewen het feit, dat er grenzen aan de groei zijn en dat op grond darvan besilisingen genomen zullen worden, die ook voor patienten met rheumatische aandoeningen betekenis hebben, is het van belang, dat rheumatologen in state aijn relevante gegevens aan te dragen. Beslissingen op het wak van de gezondheidszorg dienen wel overwogen besluiten te zijn. In de besluitvorming dient aan de wetenschappelijke kwaliteit van de gegevens en aan de verbetering van levenskwiliteit een belangrijke plats toegekend te worden. Daarbij is van belang de woordelen wan de interventies af te wegen tegen de nadeler. Het oordeel van de patient zelf is daarbij van bizondere betekenis. Besluitvorming op basis van kwalitatief goede gegevens is verre te verkiezen boven "besluitworming" zonder gefundeerde en gewogen gegevens. Dit laatste zal valk in het nadeel wan patienten zijn.

\section{Dankwoord}

Voor ik besluit, enkele dankwoorden.

Ik sprak u reeds over $5-D^{\prime} s$ en $3-D^{\prime} S$. Nu wil ik $3 V^{\prime} s$ (vaders) bedanken.

Mijn fysieke vader oveteed juist jaar geieden. Ik ben hem veel verschuidigd. Dank ook aan mijn moeder, die gelukkig nog wel arwezig kan zijn.

voorts dank ik mijn klinische en wetenschappelijke "vaderg" Nol Cats en Hars valkenburg. Het verheugt mij zeer, dat jullie 
vandaag ến van jullte vele produkten kunt aanschouwen. Hans, aan jou komt de eer toe rijn blik op de geneeskunde verruimd te hebben met eenepidemiologisch perspectief. Ik dank je woor de vele lange vormende gesprekken, die ik met jou en bij jou mocht hebben, en voor je conteptuele benadering. Ik verontschuldig me nognatis bij Carlie woor de late tijastippen farop ik jullie huls meestal verliet.

In Gus Plendrig dank lk de Vakgroep Interne Geneeskunde. Het getulgt van moed en visie in een (relatief kleine) vakgroep eer theumatologisch team wet eigen wensen op te nemen. Multidisciplinariteit in eigen gelederen kan zeer vruchtbaar $z i j n$.

Ook de Nederlandse Vereniging voor Rheumabestrijding (NVRB) dank ik bizonder wor haar beleid, hetgeen leidde tot het instellen van een leerstoel an deze undversiteit, alsmede voor hatr structurele ondersteuning. Wanuit ww verantwordelijkheid voor patienten met rheumatische aandoeningen realiseerde $u$ wat de facto "gewoon" had moeten zijn.

Marijke, Ineke, Zusanna en Carla: Ondanks een zware Burden of Care en ondanks pittige onderwisinspanringen houden jullie de moed erin. Hierbij onderwinden wijenorme hulp en enthousiaste steun van Ellen, Lilian en peggy.

Gezamenlijk zijn wij in staat onderwijs, onderzaek en patientenzorg op niveau gestalte te geven. Het verheugt me jullie teamleider of dirigent te mogen zijn en datgene wat ik van mijh leermeesters leerde, te kunnen doorgeven.

Nog even een toepasseiljk citat uit de New England Journa: van 30 november (Engl J Med 1989:321:1542): MEDICINE IS NO LONGER A MAN'S PROFESSION: The influx of women into medicine during the past two decades has rescued the profession from a serious threat to its quality". Jullie hebben dat kennelijk tijaig begrepen!

Ma de 5-D's, die 3-P's en de V's resteren de 3-ESSEN "Sietze, sjoerd en saskia" en de Hoofdletter H van Hermine. Monenten gezamenlijk doorgebracht zijn helaas vrij schaars. De werkzamheden vragen teveel tijd.

Eigenlijk had jij, Hermine, vandaag naar amerikaans voorbeeld hier nast mij moeten staan. Dat is namelijk wat je altijd doet. Wat we bereiken, berust op onze gezamelijke inspanning.

\section{Bes. IuL}

* Regionale, nationale en intemationale samenwerking breidt zich uit en zal ongetwijfeld vruchten afwerpen.

* Programmatisch (multidisciplinair) onderzoek, warin ethiologische en pathogenetische vraagstellingen gecombineerd worden met diagnostische en therapeutische problemen, biedt de meeste kans op relevante vooruitgang. Van Bedkant tot Celwand en IERUG nat de patient. De rheumatoloog kont in een dergelijke opzet de functie van "dirigent" toe.

* De koers van rheuma research wordt meer en meer bepald in overleg tussen patients, payers, providers 
* Kinische epidemiologie er population based epidemiologie leveren belangrijke bijdragen an de rheunatologie. ook met de beschikbare widielen moet de ziektelast heden ten dage sterker teruggedrongen kunnen worden. Wan belang is een goede integratie van onderzok, onderwijs en patientenzorg. ook effect meting binnen de rheumatologie moet verfijnd en geintensiveerd worden. Dit geldt ook voor onderzoek inar prognostische factoren.

* De behandeling van rheunatische aandoeningen zal zich meer en meer gaan richten op uitkomsten, die uit het oogpunt van de patient prioriteit genieten.

* De rheumatologie kan de coekomst met vertrouwen tegemoetzien. 


\section{LITZRATULWR}

Grewerton DA, Hart FD, Micolls $h$, Caffrey Manes DCo, Sturock RD: Mrylosing spordyitis and HL-A27.

Larcet $1973 ; 1: 904-907$

Eisenberg $C$ : Medicine is no longer a man's profession: or, when the men" club goes coed it's time to change the regs.

wew engl J Hed $1989 ; 321: 1542-1544$

PI1wood PM: Shattuck Lecture. Outcome measurement: a technology of patient experience.

New Engl I Med 1988:3118:1549-1556

Hess EV, Luggen ME: Remodeling the pyramid - a concept whose time has not yet come.

J Thewrimtol $1989 ; 16: 1175-1176$

Leaf A: Cost effectiveness as a chiterion for medicare coverage. New Engl J Med 1989:321:898-900

McGregor M: Technology and allocation of resources.

New Engl J Med 1989;320:118-120

Sackett DL: 2linkof Honor Lecture. Basic research, cinical research, clinical epidemiology, and general internal medicine. $J$ Gen Int Med 1987;2:919-945

Sackett DL, Haynes RE, Tugwell P: Clinical epidemiology: a basic science for clinical medicine.

Boston, Toronto: Little, Brown, 1985

Schlosstein L, Terasaki PI, Bluestone R, Pearson CM:

High association of an HL-A antigen, W27, with ankylosing spondylitis.

New Engl I Med 1973;288:704-706

Stastny P: Immunogenetic factors in rheumatoid arthritis. Clin Rheum Dis $1977 ; 3: 315-332$

Paal E, Jacobs JW, Seydel ER, Wiegman 0 , Rasker JJ: Evaluation of the Dutch Arthritis Impact Measurement scales (DUTCH AIMS) in patients with thewataid arthritis.

Bis I Rheumatol 1989;28:487-491

mugwell $\mathbb{P}$, Bennett $K J$, Sackett $D L$, Haynes RB: The measurement itarative loop: a framework for the critical appraisal of reed, benefits, and costs of health interventions.

J Chron Dis $1985 ; 38: 339-351$ 
Var der Linden SM, Valkenburg HA, de Jongh $\mathrm{BN}$, Cats $A$ :

The risk of developing ankylosing spondylitis in Ha-B27 positive individuals: a comparison of relatives of spondylitis patients with the general population.

Arthritis Rheum $1984 ; 27: 241-249$

Wiske KR, Healey LA: Remodeling the pyranid - a concept whose time has come.

J Rheumatol $1989 ; 16: 565-567$ 